\title{
Effect of Absorbent Tetracycline-Loaded Membrane Used in the Reduction of Periodontal Pockets: An In Vivo Study
}

\author{
Priscilla Barbosa Ferreira SOARES ${ }^{1}$ \\ Helder Henrique Machado de MENEZES ${ }^{2}$ \\ Marina de Melo NAVES ${ }^{1}$ \\ Eulázio Mikio TAGA ${ }^{3}$ \\ Denildo de MAGALHÃES ${ }^{1}$
}

\author{
${ }^{1}$ Department of Periodontology and Implantology, Dental School, \\ Federal University of Uberlândia, Uberlândia, $M G$, Brazil \\ ${ }^{2}$ Department of Periodontology and Implantology, HD Postgraduate Dental Education Center, Uberlândia, MG, Brazil \\ ${ }^{3}$ Department of Biochemistry, Dental School, University of São Paulo, Bauru, SP, Brazil
}

\begin{abstract}
This clinical study evaluated the influence of scaling and root planning (SRP), with and without the use of tetracycline-loaded bovine absorbent membrane, in the reduction of periodontal pockets according to 3 parameters: probing pocket depth (PPD), bleeding on probing (BOP) and plaque index (PI). Twenty-four patients were selected totalizing 144 random teeth divided in 2 groups ( $\mathrm{n}=72$ teeth) - control (SRP) and experimental (SRP with tetracycline-loaded absorbent membrane). PPD, BOP and PI were determined before and 28 days after the treatment. In all patients, the PPD values at the end of the treatment were always lower than the baseline values. There was a reduction of the PI for both treatments, but it was more evident on the experimental group. In conclusion, the use of tetracycline-loaded absorbent membrane could result in a better prognosis compared to scaling and root planning after only 28 days of evaluation.
\end{abstract}

Key Words: local drug delivery, scaling and root planning, periodontal disease, tetracycline.

\section{INTRODUCTION}

The occurrence of periodontal disease is conditioned to the local settling of specific bacteria (1), where the progression is diagnosed by the involvement of support and covering structure levels (2). In almost all cases, the periodontal therapeutic actions are aimed at mechanical events, for the elimination of etiologic factors, predisposition and sequels of surgical corrections. These protocols cause alteration of the subgingival microbiota by means of decontamination of the cementum and dentin $(3,4)$. Scaling and root planning (SRP) is still the most common and conservative periodontal procedure for the treatment of periodontal disease
$(3,5)$. The good results achieved with this conservative periodontal therapy are associated to the effectiveness of the root surface instrumentation into periodontal pockets (6). Limitations of SRP include the difficulty of instrument access and visualization of the action of scaling $(7,8)$. These limitations are more significant in probing depths $\geq 5 \mathrm{~mm}(9)$.

Adjunct protocols to mechanical treatment are decisive to ensure successful outcomes in periodontal therapy. Local and systemic antimicrobial agents have been widely indicated as a complementary resource for SRP (10). Direct administration into the periodontal pockets produces adequate concentrations of the active antimicrobial agent in the crevicular fluid, without

Correspondence: Prof. Dr. Denildo de Magalhães, Faculdade de Odontologia, Universidade Federal de Uberlândia, Área de Periodontia e Implantodontia, Avenida Pará, 1720, Campus Umuarama, Bloco 2G, 38405-902 Uberlândia, MG, Brasil. Tel: +55-34-3218-2255. Fax: +55-34-3218-2279. e-mail: denildo@foufu.ufu.br 
causing any damage to the circumjacent tissues (11). Consequently, serum levels are not produced, reducing the frequent side effects associated to the systemic administration (11). Among the chemical agents used in the treatment of periodontal pockets, tetracycline hydrochloride has stood out $(9,12)$ because of its efficiency against subgingival microbiota, substantivity, adsorption capacity to dental surface and inhibition of bacterial protein synthesis $(13,14)$. Additional advantages of tetracycline applied to dentin are that it increases the binding of extracellular matrix glycoprotein fibronectin the dentin and stimulated fibroblast growth and attachment (13). This substance has potent inhibitory effects on metalloproteinase (15) osteoclast function (15) and has antiinflammatory properties (13).

Non-mechanic resources used to eliminate the subgingival microbiota consist in the local administration of antimicrobial agents with adequate concentration into the periodontal pocket using a specific vehicle (16). Two hypotheses are tested in this clinical study: 1) the use of tetracycline-loaded bovine absorbent membrane as local delivery device increases the repair of periodontal pockets in human patients with periodontal disease; 2) the membrane performance depends on the region on which it is used. For such purpose, it was evaluated the influence of SRP with or without the use of bovine absorbent membrane loaded with tetracycline hydrochloride in the reduction of probing pocket depth (PPD), bleeding on probing (BOP) and plaque index (PI).

\section{MATERIAL AND METHODS}

Twenty-four individuals, being 11 males (mean age $=42.03 \pm 13.78$ years) and 13 females (mean age $=39.64 \pm 12.05$ years), in good general health condition and with advanced chronic periodontitis were selected after approval of the research project by the Research Ethics Committee of the Federal University of Uberlândia (protocol \#097/04). Patients that presented an equal number of single-rooted teeth per hemiarch $(\mathrm{n}=72)$ with periodontal pockets in the 4 faces presenting PPD $\geq 5 \mathrm{~mm}$ were enrolled in the study, totalizing 144 teeth. In order to confirm the clinical diagnosis of the presence of periodontal disease all patients were subjected to $\mathrm{x}$-ray analysis.

Two treatment protocols were assigned to the same patient and applied in each hemiarch, randomly in sequence and region. The treatment protocol of the control group (C) consisted of SRP in 72 teeth. In the other hemiarch, the protocol of the experimental group (TM) consisted in the association of tetracycline-loaded absorbent membrane use after SRP in 72 teeth. A single operator performed all clinical procedures.

Three parameters were examined: 1. PPD: a Williams type millimeter periodontal probe (Hu-Friedy, Chicago, IL, USA) was gently introduced softly into the gingival sulcus until resistance to the penetration was felt (Fig. 1). Four PPD measurements were done per tooth, one on each face - mesial (M), distal (D), lingual (L) and buccal (B), totalizing 288 face measurements per group before SRP (baseline) and 28 days after completion of the treatment protocols of groups C and TM (final); 2. BOP: the occurrence of bleeding on probing for depth pocket measurement was evaluated. Faces with positive result were considered those in which bleeding occurred during probing or after the maximum interval of $15 \mathrm{~s}$ after probing; and 3. PI: determined according to Silness and Löe (17).

The protocol of the control group (C) involved SRP, using Gracey curettes under local anesthesia. This treatment aimed to eliminate calculus deposits, modified cement and dentin of pathological process. SRP duration was standardized for all teeth. This procedure was performed in a single clinical session and the baseline PPD and BOP values were taken immediately after this procedure.

The protocol of the experimental group (TM) involved the use of local drug delivery devices using before the parameters analysis. Absorbent membranes

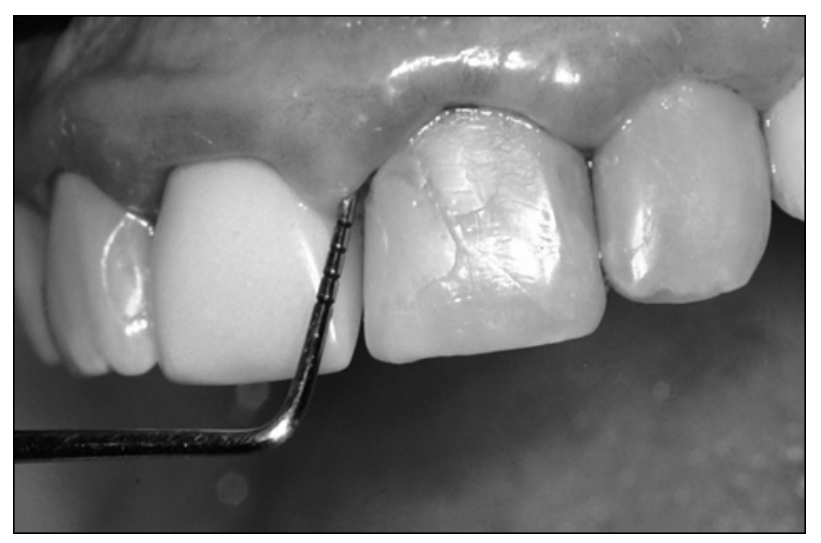

Figure 1. Probing pocket depth. A Williams type millimeter periodontal probe was gently introduced softly into the gingival sulcus until resistance to the penetration was felt. 
of bovine origin (Gen-derm/Baumer, Mogi Mirim, SP, Brazil), with $0.2 \mathrm{~mm}$ of thickness, were immersed in $5 \%$ tetracycline hydrochloride solution and left drying on glass plates at room temperature. The tetracyclineloaded membranes were cut with a circular scalpel (Odontex, Curitiba, PR, Brazil) into $3.0 \mathrm{~mm}$-diameter samples. The devices were packed in surgical envelopes (Baumer) for ethylene oxide sterilization. Immediately after SRP, the device was inserted in the periodontal pocket, at each cervical face of the tooth. For this procedure, the operator used millimeter periodontal probe, introducing the device carefully and covering it totally with gingival tissues (Fig. 2). After 28 days, group C and TM patients were evaluated using the same PPD, BOP and PI parameters (Fig. 3).

The PPD data were subjected to 2-way ANOVA, with the treatment type factor in 2 levels ( $\mathrm{C}$ and use of $\mathrm{TM}$ ) and the site factor in 4 levels (mesial, distal, buccal

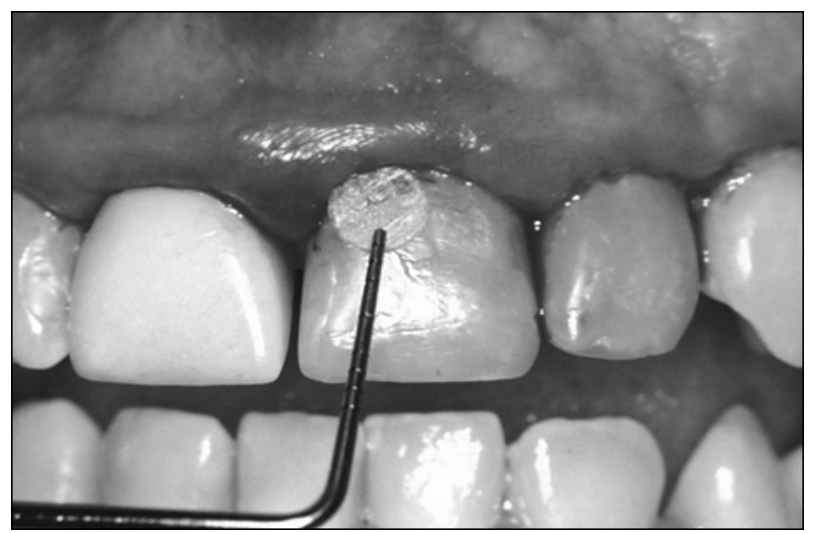

Figure 2. Careful introduction of the tetracycline-loaded membrane into the periodontal pocket using a millimeter periodontal probe after scaling and root planing. and lingual), followed by the Tukey's HSD test $(\alpha=0.05)$. To compare the baseline and final data of each treatment protocol in each site, paired Student's t-test was applied $(\alpha=0.05)$. BOP data were described by baseline and final mean values and percentage distribution for treatment protocols.

\section{RESULTS}

The PPD and BOP values for the all groups are described in Table 1. Two-way ANOVA showed significance for the site and treatment protocol factors, but no significant difference was found for the interaction between the site and treatment factors. The use of tetracycline-loaded membrane resulted in a significant PPD reduction compared to the control group, irrespective of the analyzed site (Table 1). In all patients and sites, the PPD values at the end of the treatment were

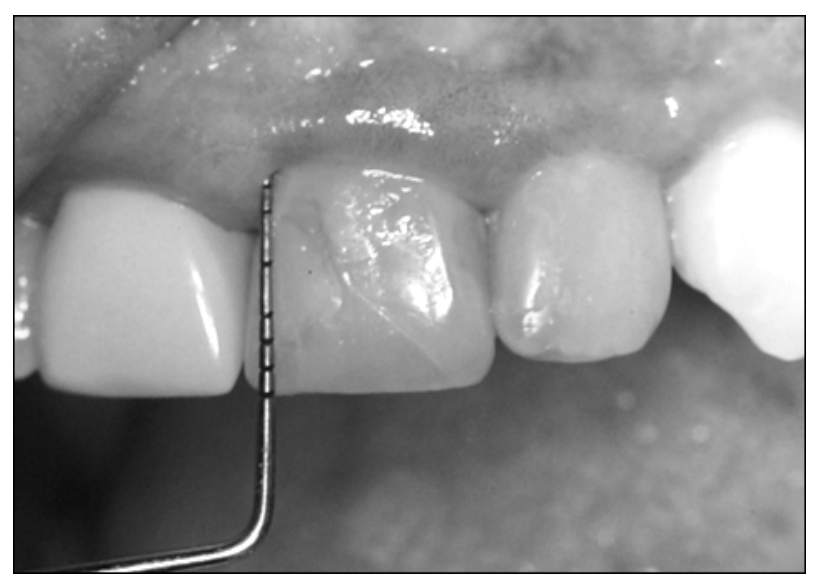

Figure 3 . The patients were revaluated after 28 days using the same PPD, BOP and PI parameters.

Table 1. Means and standard deviation of probing pocket depth $(\mathrm{mm})$ and Tukey's HSD test statistical categories.

\begin{tabular}{|c|c|c|c|c|c|c|c|c|}
\hline & \multicolumn{2}{|c|}{ Mesial } & \multicolumn{2}{|c|}{ Buccal } & \multicolumn{2}{|c|}{ Distal } & \multicolumn{2}{|c|}{ Lingual } \\
\hline & $\mathrm{C}$ & $\mathrm{TM}$ & $\mathrm{C}$ & $\mathrm{TM}$ & $\mathrm{C}$ & TM & $\mathrm{C}$ & $\mathrm{TM}$ \\
\hline Initial & $5.9 \pm 0.7^{\mathrm{bA}}$ & $5.9 \pm 0.6^{\mathrm{bA}}$ & $5.5 \pm 0.5^{\mathrm{bA}}$ & $5.6 \pm 0.6^{\mathrm{bA}}$ & $6.2 \pm 0.8^{\mathrm{bA}}$ & $6.1 \pm 0.7^{\mathrm{bA}}$ & $5.7 \pm 0.7^{\mathrm{bA}}$ & $5.8 \pm 0.7^{\mathrm{bA}}$ \\
\hline Final & $4.5 \pm 0.8^{\mathrm{aB}}$ & $3.3 \pm 0.8^{\mathrm{aA}}$ & $4.0 \pm 0.6^{\mathrm{aB}}$ & $3.0 \pm 0.8^{\mathrm{aA}}$ & $4.8 \pm 0.9^{\mathrm{aB}}$ & $3.5 \pm 0.7^{\mathrm{aA}}$ & $4.6 \pm 0.8^{\mathrm{aB}}$ & $3.4 \pm 0.8^{\mathrm{aA}}$ \\
\hline
\end{tabular}

C: control group; TM: experimental group. Different letters indicate statistically significant difference $(p<0.05)$. Uppercase letters mean horizontal line comparison for each face (treatment methods) and lowercase letters mean vertical line comparison (period). 
always lower than the baseline values.

PPD reduction in the lingual site was similar to the proximal sites, which, in turn, were similar to buccal sites. However, there was more accentuated reduction in PPD in the buccal site compared to the lingual site (Table 1).

BOP reduction was observed for both groups after all protocols tested, but it was more evident in the experimental group (Fig. 4).

\section{DISCUSSION}

The results of this study supported the hypothesis that the use of tetracycline-loaded membrane resulted in significant improvement for the PPD and PI parameters. This study showed that the tetracycline-loaded membrane as local delivery device increases the periodontal pocket repair. In addition, the probing depth was significantly lower in the after all treatments compared to the baseline values, irrespective to the treatment method and the region tested (Table 1).

Although the buccal adequacy achieved by mechanical procedures of SRP are important in the reduction of the clinical inflammation parameters $(3,18,19)$. The achievement of the adequate clinical results has been related to the operator ability in accessing all depth of periodontal pockets. In case it is not possible, the pathology persistence probably will persist, requiring complementary treatment $(4,9)$. According to Loesche (4), BOP is a characteristic of the inflammatory activity of periodontal disease, being an important symptom of this pathology. The baseline BOP values for both groups (C and TM) were $100 \%$ (Fig. 1). This study confirmed that all patients presented contaminated areas by periodontal disease. However, when was compared baseline and

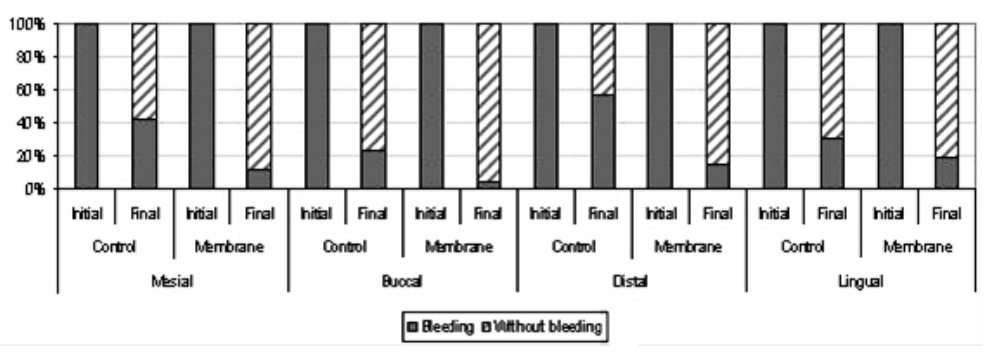

Figure 4. Percent distribution of bleeding of probing occurrence in the initial and final periods in the control and experimental groups at the analyzed sites. final values, after SRP, it is possible to observe that the control group presented reduction level of $60-80 \%$, which may confirm the success of this procedure (5).

The benefits of tetracycline include not only bactericidal and bacteriostatic activity in periodontal disease, but also adsorption to dental surface and capacity to increase fibroblasts attachment to root surface (13). The use of tetracycline-loaded membrane resulted in significantly greater reduction in PPD parameters compared to the isolated execution of SRP, irrespective of the analyzed region. The difference between the control and experimental group probably is related to the limited action of SRP. The use of tetracycline after SRP revealed efficient on clinical insertion profit, which can promote good benefits without use of surgical therapies for chronic periodontitis (10). Although oral adequacy using SRP is efficient in the reduction of clinical inflammation parameters $(3,18,19)$, reach adequate clinical outcomes depends on the operator's ability. In case of pathology persistence, complementary therapeutic actions are required by the of use local delivery devices $(4,9)$. The performance of the tetracycline-loaded membrane probably depends on the tooth face on which it is used. The action in the lingual face was less effective than into the buccal surface. These results can be related to the greater facility to access the buccal cervical area during the SRP.

The inflammation is clinically evidenced by the bleeding on probing with the presence of bacterial plaque and calculus. After clinical procedures of scaling and root planing the gingival index is reduced $(4,5)$. When comparing the bleeding levels before and after the SRP was verified that the levels were significantly reduced after the tetracycline membrane use (Fig. 1). This procedure revealed efficient reduction for the bleeding levels mainly in into the proximal faces (Fig. 1). Yukna (20) demonstrated that mechanical instrumentation of interproximal areas is far more difficulty to be done, usually causing more bleeding and pain, which may reflect in less effectiveness of therapeutic procedure in this region (20). This aspect can explain the differences between the control and experimental group in this region.

Within the limitations of this study, it may be concluded that PPD decreased after all treatment protocols. 
However the use of tetracycline-loaded membrane resulted in significant reduction in the PPD and in the PI when compared with the control group for all analyzed regions. It was also verified, greater reduction in the bleeding levels when the tetracycline-loaded membrane with was used higher intensity in the proximal faces. It is evident that SRP constitutes an essential procedure, but local tetracycline delivery using especial devices could be an important coadjutant for periodontal pocket therapy.

\section{RESUMO}

Este estudo clínico avaliou a influência da raspagem e alisamento radicular, com e sem a utilização de membrana absorvível de liberação de tetraciclina na redução de bolsa periodontal utilizando 3 parâmetros: sondagem da profundidade de bolsa, sangramento à sondagem e índice de placa. Vinte e quatro pacientes foram selecionados totalizando 144 dentes aleatoriamente divididos em 2 grupos $(\mathrm{n}=72$ dentes $)$ - controle (raspagem e alisamento radicular) e experimental (raspagem e alisamento radicular e utilização de membrana absorvível de liberação de tetraciclina). Antes da execução do tratamento foram determimados profundidade de bolsa, sangramento à sondagem e índice de placa. Os pacientes foram avaliados usando os mesmos parâmetros após 28 dias. Os valores da sondagem da profundidade de bolsa foram sempre menores no final do tratamento quando comparado ao início. Houve redução no índice de placa para as 2 formas de tratamento, apesar de ter sido mais evidente no grupo experimental. Concluiu-se que o uso da membrana absorvível de liberação de tetraciclina pode resultar em melhor prognóstico quando comparado apenas com a raspagem e alisamento radicular, após 28 dias de análise.

\section{REFERENCES}

1. Andrian E, Grenier D, Rouabhia M. In vitro models of tissue penetration and destruction by Porphyromonas gingivalis. Infect Immun 2004;72:4689-4698.

2. Wennstrom JL, Tomasi C, Bertelle A, Dellasega E. Full-mouth ultrasonic debridement versus quadrant scaling and root planing as an initial approach in the treatment of chronic periodontitis. J Clin Periodontol 2005;32:851-859.

3. Drisko CH. Nonsurgical periodontal therapy. Periodontol 2000 2001;25:77-88.

4. Loesche WJ, Giordano JR, Soehren S, Kaciroti N. The nonsurgical treatment of patients with periodontal disease: results after five years. J Am Dent Assoc 2002;133:311-320.

5. Johnson LR, Stoller NH, Polson A, Harrold CQ, Ryder M, Garrett $\mathrm{S}$. The effects of subgingival calculus on the clinical outcomes of locally-delivered controlled-release doxycycline compared to scaling and root planing. J Clin Periodontol 2002;29:87-91.

6. Caffesse RG, Mota LF, Morrison EC. The rationale for periodontal therapy. Periodontol 2000 1995;9:7-13.

7. Santos VR, Lima JA, De Mendonça AC, Braz Maximo MB, Faveri M, Duarte PM. Effectiveness of full-mouth and partial-mouth scaling and root planing in treating chronic periodontitis in subjects with type 2 diabetes. J Periodontol;2009;80:1237-1245.

8. Romeo U, Palaia G, Botti R, Leone V, Rocca JP, Polimeni A. Non-surgical periodontal therapy assisted by potassium-titanylphosphate laser: a pilot study. Lasers Med Sci;2009 [Ahead of print; Published online: Nov 21.]

9. Van der Weijden GA, Timmerman MF. A systematic review on the clinical efficacy of subgingival debridement in the treatment of chronic periodontitis. J Clin Periodontol 2002;29:5571.

10. Wennstrom JL, Newman HN, MacNeill SR, Killoy WJ, Griffiths GS, Gillam DG, et al.. Utilisation of locally delivered doxycycline in non-surgical treatment of chronic periodontitis. A comparative multi-centre trial of 2 treatment approaches. $\mathrm{J}$ Clin Periodontol 2001;28:753-761.

11. Rams TE, Slots J. Local delivery of antimicrobial agents in the periodontal pocket. Periodontol 2000 1996;10:139-159.

12. Greenstein G, Polson A. The role of local drug delivery in the management of periodontal diseases: a comprehensive review. J Periodontol 1998;69:507-520.

13. Seymour RA, Heasman PA. Tetracyclines in the management of periodontal diseases. A review. J Clin Periodontol 1995;22:22-35.

14. Terranova VP, Franzetti LC, Hic S, DiFlorio RM, Lyall RM, Wikesjö UM, et al.. A biochemical approach to periodontal regeneration: tetracycline treatment of dentin promotes fibroblast adhesion and growth. J Periodontal Res 1986;21:330-337.

15. Golub LM, Ramamurthy NS, McNamara TF, Greenwald RA, Rifkin BR. Tetracyclines inhibit connective tissue breakdown: new therapeutic implications for an old family of drugs. Crit Rev Oral Biol Med 1991;2:297-321.

16. Salvi GE, Mombelli A, Mayfield L, Rutar A, Suvan J, Garrett $\mathrm{S}$, et al.. Local antimicrobial therapy after initial periodontal treatment. J Clin Periodontol 2002;29:540-550.

17. Silness J, Löe H. Periodontal disease in pregnancy. II. Correlation between oral hygiene and oral condition. Acta Odontol Scand 1964;22:121-135.

18. Hung HC, Douglass CW. Meta-analysis of the effect of scaling and root planing, surgical treatment and antibiotic therapies on periodontal probing depth and attachment loss. J Clin Periodontol 2002;29:975-986.

19. Kaldahl WB, Kalkwarf KL, Patil KD, Dyer JK, Bates RE Jr. Evaluation of four modalities of periodontal therapy. Mean probing depth, probing attachment level and recession changes. J Periodontol 1988;59:783-793.

20. Yukna RA, Scott JB, Aichelmann-Reidy ME, LeBlanc DM, Mayer ET. Clinical evaluation of the speed and effectiveness of subgingival calculus removal on single rooted teeth with diamond-coated ultrasonic tips. J Periodontol 1997;68:436-442.

Accepted September 15, 2009 